\title{
Age-Related Changes in Orienting Attention in Time
}

\author{
Theodore P. Zanto, ${ }^{1}$ Peter Pan, ${ }^{1}$ Helen Liu, ${ }^{1}$ Jacob Bollinger, ${ }^{1}$ Anna C. Nobre,,${ }^{2}$ and Adam Gazzaley ${ }^{1}$ \\ ${ }^{1}$ Departments of Neurology and Physiology, University of California San Francisco, San Francisco, California 94158, and ${ }^{2}$ Department of Experimental \\ Psychology, University of Oxford, Oxford, OX1 3UD United Kingdom
}

Temporal cues guide attentional resources toward relevant points in time, resulting in optimized behavioral performance. Although deficits in aspects of attention have been documented in older adults, it remains unknown whether the critical ability to orient attention in time is affected by normal aging. To address this, younger and older adults participated in a temporally cued target-response experiment while electroencephalographic data were recorded. Three conditions (one detection and two discrimination tasks) were used to manipulate task complexity. Response times show that younger adults, but not older adults, used temporal cues to enhance performance regardless of task complexity. Similarly, alpha band activity $(8-12 \mathrm{~Hz})$ and the contingent negative variation preceding targets indicated that only younger adults engaged prestimulus, anticipatory neural mechanisms associated with temporal cues. Overall, these results provide novel evidence that older adults do not use temporal cues to orient attention in time and support an expectation deficit in normal aging.

\section{Introduction}

Our ability to direct the focus of limited attentional resources toward task-relevant information enhances behavioral performance (James, 1890). This attentional orienting, or selective attention, is thought to optimize performance by biasing neural processing of relevant items and suppressing representations of irrelevant distractions (Moran and Desimone, 1985; Fuster, 1990). Although it has been documented that older adults have deficits in attentional orienting (Dempster, 1992) and expectation-driven neural processes (Vallesi et al., 2009; Bollinger et al., 2011), it remains unknown whether the ability to orient attention to prespecified points in time is affected by normal aging. We hypothesized that older adults experience behavioral deficits in temporal attention and accompanying underlying neural alterations.

Extensive research has reported the beneficial effects of cueing attention to a spatial location, such that response times during a target detection task are speeded when the target appears at a cued location (Posner, 1980; Posner et al., 1984; Yantis and Jonides, 1990). Furthermore, it has been known for nearly 100 years that a predictable interval between a warning and a target stimulus results in speeded response times to the target (Woodrow, 1914). The warning serves to cue an impending target stimulus, thereby allowing temporal expectation to be established when the time interval is predictable. However, warning-signal tasks cannot address the flexibility of cognitive control because the time period between the warning and target must remain

Received March 4, 2011; revised June 21, 2011; accepted July 11, 2011.

Author contributions: T.P.Z., J.B., A.C.N., and A.G. designed research; T.P.Z., P.P., H.L., and J.B. performed research; T.P.Z., P.P., and H.L. analyzed data; T.P.Z., A.C.N., and A.G. wrote the paper.

This work was supported by the National Institutes of Health Grants 4F32AG030249-03 (to T.P.Z.) and 5R01AG030395 (to A.G.). We thank Victor Barres and Celya Gruson-Daniel for their assistance.

Correspondence should be addressed to Theodore Zanto, University of California San Francisco, MC2240, 600 16th Street, Genentech Hall, Room N474, San Francisco, CA 94158. E-mail: theodore.zanto@ucsf.edu.

DOI:10.1523/JNEUROSCI.1149-11.2011

Copyright $\odot 2011$ the authors $\quad 0270-6474 / 11 / 3112461-10 \$ 15.00 / 0$ consistent from one trial to the next. Research assessing the cueing effect on attention in the time domain has indicated that preknowledge about when a target will appear improves response time (Coull and Nobre, 1998; Miniussi et al., 1999; Lange and Röder, 2006). These studies used a target-detection task and probed the influence of temporal attention on perception. The data suggest that the deployment of anticipatory resources for perceptual processes such as detection is under flexible cognitive control, as opposed to a rigid process with a set optimal time course.

To evaluate whether temporal attention is affected by normal aging, younger and older adults participated in a temporally cued target-response task (Fig. 1) while EEG data were recorded. Similar to previous research on the role of temporal attention in target detection (Miniussi et al., 1999), it was expected that younger adults would only use the cues preceding a short foreperiod to benefit performance, and not benefit from cues indicating a long foreperiod. This is because targets following a long foreperiod are inherently cued by the conditional probability of their occurrence (i.e., if a target does not appear after the short time period, it is guaranteed to occur after the long time period transpires). Most germane to this study, it was hypothesized that older adults would not use temporal cues to benefit perceptual performance, and this would be accompanied by alterations in pretarget neural processing. Finally, age-related changes were hypothesized to be more pronounced as task complexity increased from detection, to go/no-go, to the forced-choice condition.

\section{Materials and Methods}

Participants. Twenty healthy young adults (mean age, 24.6 years; range, $19-33$ years; 7 females) and 21 older adults (mean age, 69.7 years; range, 62-82 years; 15 females) gave informed consent to participate in the study approved by the Committee on Human Research at the University of California in San Francisco. All participants had normal or correctedto-normal vision and were screened to ensure they were healthy; had no history of neurological, psychiatric, or vascular disease; were not de- 


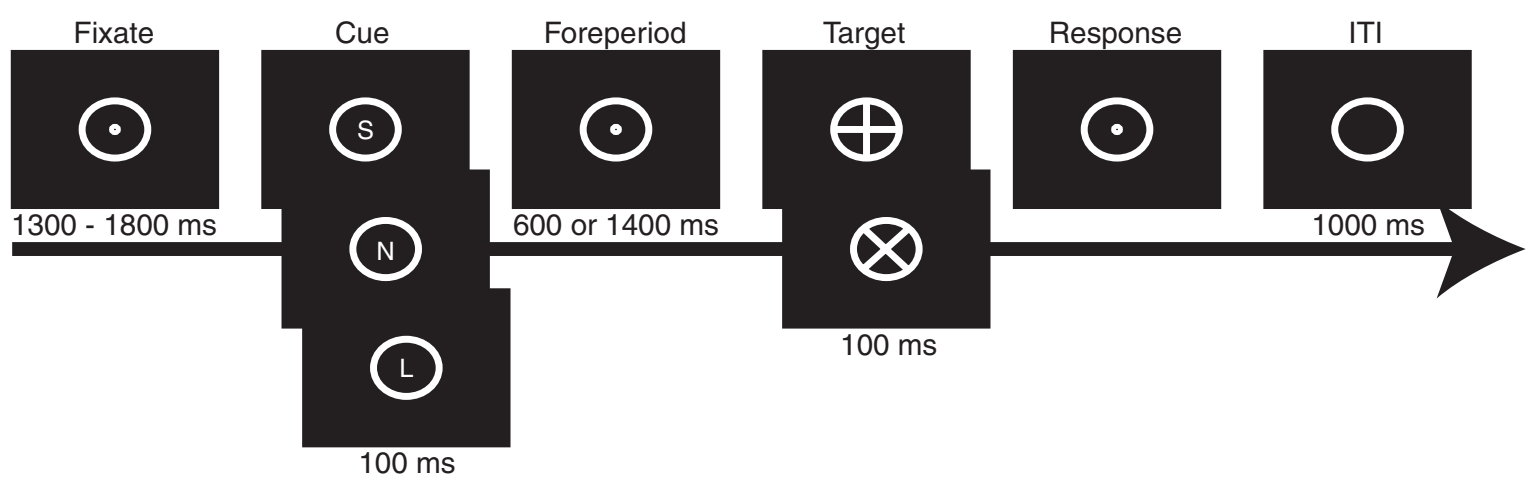

Figure 1. Experimental paradigm. The cue and target were randomly selected for each trial from three different cue types and two different target types. S, Short foreperiod (600 ms); L, long foreperiod (1400 ms); $\mathrm{N}$, neutral cue ( 600 or $1400 \mathrm{~ms}$ ); $\mathrm{ITl}$, intertrial interval. The meaning of the target ( $\mathrm{x}$ or + ) was contingent on the experimental condition (detection, go/no-go, or forced choice).

Table 1. Mean scores from the neuropsychological evaluation in older adults

\begin{tabular}{lcc}
\hline Neuropsychological test & Mean & SE \\
\hline Mini-mental state examination & 29.5 & 0.2 \\
Geriatric depression scale & 1.9 & 0.5 \\
CVLT: Trial 5 recall & 13.5 & 0.6 \\
CVLT: Short delay free recall & 12.3 & 0.7 \\
CVLT: Short delay cued recall & 13.0 & 0.5 \\
CVLT: Long delay free recall & 12.8 & 0.7 \\
CVLT: Long delay cued recall & 13.1 & 0.6 \\
Memory for modified Rey & 13.1 & 0.6 \\
Calculation ability (out of 5) & 4.9 & 0.1 \\
WAIS-R: Backward digit span & 5.4 & 0.4 \\
WAIS-R: Digit symbol & 53.5 & 1.8 \\
Trail making test: A & $30.0 \mathrm{~s}$ & $1.4 \mathrm{~s}$ \\
Trail making test: B & $70.2 \mathrm{~s}$ & $3.7 \mathrm{~s}$ \\
Stroop: Color naming & 89.9 & 2.0 \\
Stroop: Color-word naming & 52.7 & 2.9 \\
Semantic fluency & 22.4 & 1.3 \\
Phonemic fluency & 15.4 & 1.4 \\
\hline
\end{tabular}

All individual scores were within two standard deviations of the normative values. CVLT, California Verbal Learning Test; WAIS-R, Wechsler Adult Intelligence Scale-Revised.

pressed; and were not taking any psychotropic or hypertensive medications. Visual acuity was checked for each participant using a Snellen chart and corrective lenses were used as necessary to achieve 20/40 vision or better. Additionally, all participants were required to have 12 years minimum education.

Neuropsychological testing. To ensure older adults were comparable to their age-matched peers, participants in the older age group were required to score within 2 SDs of control values on 13 neuropsychological tests. The neuropsychological evaluation consisted of tests designed to assess general intellectual function (Mini-Mental Status Exam; Folstein et al., 1975), verbal learning (California Verbal Learning Test, second version; Delis et al., 2000), geriatric depression (Geriatric Depression Scale; Yesavage et al., 1982), visual-spatial function (copy of a modified Rey-Osterrieth figure), visual-episodic memory (memory for details of a modified Rey-Osterrieth figure), visual-motor sequencing (trail making test A and B; Reitan, 1958; Tombaugh, 2004), phonemic fluency (words beginning with the letter D), semantic fluency (animals), calculation ability (arithmetic), executive functioning (Stroop interference test; Stroop, 1935), working memory and incidental recall (backward digit span and digit symbol; Wechsler Adult Intelligence Scale-Revised; Wechsler, 1981). All neuropsychological test scores are summarized in Table 1.

Stimuli and experimental procedure. Stimuli were presented through E-Prime software (Psychology Software Tools) run on a Dell Optiplex GX620 with a 22" Mitsubishi Diamond Pro 2040U CRT monitor. Participants were seated in a dark room, $100 \mathrm{~cm}$ from the monitor, with a chin rest. A white circle with a $7 \mathrm{~cm}$ inner $(8 \mathrm{~cm}$ outer $)$ diameter was centered on a black background during the experiment. Figure 1 depicts one experimental trial. Participants were instructed to fixate on a dot $(0.5$ $\mathrm{cm}$ diameter) located in the center of the circle. The fixation period was between 1300 and $1800 \mathrm{~ms}$ (selected randomly). A $100 \mathrm{~ms}$ cue appeared and contained one of three letters: S, L, or N. These letters indicated the duration of the foreperiod $(\mathrm{S}=$ short $=600 \mathrm{~ms} ; \mathrm{L}=$ long $=1400 \mathrm{~ms}$; $\mathrm{N}=$ neutral $=600$ or $1400 \mathrm{~ms}$ ). Thus, only $\mathrm{S}$ and $\mathrm{L}$ cues predicted when the target would appear and will be referred to as PS (predictive short) and PL (predictive long), respectively. The neutral cues will be referred to as NS and NL, depending on whether the N preceded a short or long foreperiod, respectively. One of the four cue types (PS, PL, NS, NL) was selected randomly on each trial, each with a $25 \%$ probability. Following the foreperiod, a target appeared with either an $\mathrm{x}$ or a + inside the white circle, each with a $50 \%$ probability of occurrence. Participants were instructed to respond with a button press as quickly and accurately as possible to the target. Responses were contingent on three different task conditions. The detection condition required participants to respond to either target type $(\mathrm{x}$ or + ) by pressing two buttons simultaneously with their left and right thumbs. The go/no-go discrimination condition required participants to press both buttons simultaneously when the target was a + , whereas responses were to be withheld if the target was an $\mathrm{x}$. The forced-choice discrimination condition required participants to press the left button for $\mathrm{x}$ targets and the right button for + targets.

Data acquisition. Data were recorded during six blocks (two per condition) lasting $\sim 10 \mathrm{~min}$ each, yielding 80 epochs of data for each cue type per condition. Electrophysiological signals were recorded with a BioSemi ActiveTwo 64-channel EEG acquisition system in conjunction with BioSemi ActiView software (Cortech Solutions). Signals were amplified and digitized at $1024 \mathrm{~Hz}$ with a 24-bit resolution and no on-line filter. All electrode offsets were maintained between $\pm 20 \mathrm{mV}$.

Data analysis. Raw EEG data were referenced to the average off-line and high-pass filtered at $0.1 \mathrm{~Hz}$ with a zero-phase shift (noncausal) finite impulse response Butterworth filter. Eye artifacts were removed through an independent component analysis by excluding components consistent with topographies for blinks, eye movements, and the electrooculogram time series. Data were segmented into epochs beginning $200 \mathrm{~ms}$ precue onset and ending $800 \mathrm{~ms}$ posttarget onset. This preprocessing was conducted in Brain Vision Analyzer (Cortech Solutions) and exported to Matlab (Mathworks) for all subsequent analyses. To minimize spurious peak event-related potential (ERP) measures, epochs were low-pass filtered at $30 \mathrm{~Hz}$ with a zero-phase shift (noncausal) finite impulse response Butterworth filter. Epochs that exceeded a voltage threshold of $\pm 75 \mu \mathrm{V}$ were rejected. A $200 \mathrm{~ms}$ precue baseline was subtracted from each epoch before calculating the ERP. Peak P1 values were chosen as the largest local peak amplitude between 50 and 150 ms poststimulus onset, the N1 was identified as the most negative local peak amplitude between 120 and 220 $\mathrm{ms}$, and the P3 values were chosen as the largest local peak amplitude between 300 and $500 \mathrm{~ms}$ poststimulus onset. These temporal windows do not reflect the range of observed peak latencies, but rather serve to guide selection of ERP measures, as previously reported (Gazzaley et al., 2008; Zanto et al., 2010). Mean amplitudes were measured by averaging over a temporal window (10 ms for P1 and N1; $25 \mathrm{~ms}$ for P3) centered around 
Table 2. Summary of all response times (in $\mathrm{ms}$ ) from each age group per condition and cue type

\begin{tabular}{lll}
\hline & \multicolumn{2}{l}{ Response times } \\
\cline { 2 - 3 } Cue type & Younger, mean (SE) & Older, mean (SE) \\
\hline Detection & & \\
PS & $301(20)$ & $487(61)$ \\
NS & $354(16)$ & $436(42)$ \\
PL & $305(11)$ & $350(26)$ \\
NL & $308(13)$ & $348(23)$ \\
Go/no-go & & \\
PS & $375(13)$ & $453(19)$ \\
NS & $440(12)$ & $464(21)$ \\
PL & $408(12)$ & $470(21)$ \\
NL & $417(13)$ & $469(20)$ \\
Discrimination & & \\
PS & $462(22)$ & $577(27)$ \\
NS & $529(27)$ & $602(31)$ \\
PL & $507(32)$ & $612(43)$ \\
NL & $513(38)$ & $599(29)$ \\
\hline
\end{tabular}

each individual participant's peak before statistical analysis. Alpha band $(8-12 \mathrm{~Hz})$ activity was acquired via complex Morlet wavelets (family ratio: $f_{\mathrm{o}} / \sigma_{f}=7$ ) applied to the epoched data before low-pass filtering. The standard deviations in the time and frequency domain can be calculated by $\sigma_{f}=1 /\left(2 \pi \sigma_{t}\right)$, resulting in $\sigma_{f}=1.4 \mathrm{~Hz}$ and $\sigma_{t}=111 \mathrm{~ms}$ at $10 \mathrm{~Hz}$. Induced alpha power was calculated from the wavelet coefficients by averaging the magnitude of alpha activity over trials, effectively ignoring phase information (Tallon-Baudry and Bertrand, 1999). Alpha power was then normalized for each participant by calculating the z-score over time from data that was concatenated across all conditions and cue types. Contingent negative variation (CNV) and alpha band measures of expectation are best observed immediately preceding an expected event (Brunia and Damen, 1988; Foxe et al., 1998); therefore, a temporal window was defined during the foreperiod over the $200 \mathrm{~ms}$ before target onset. Three posterior-occipital regions of interest (ROIs) were created by averaging over five electrodes from the central (CPZ, PZ, POZ, P1 P2), left (P7, P9, PO3, PO7, O1), and right ( $\left.\mathrm{P} 8, \mathrm{P} 10, \mathrm{PO} 4, \mathrm{PO} 8, \mathrm{O}_{2}\right)$ hemisphere, consistent with the topographical distribution of the visual ERP. One ROI was chosen for ERP analysis as defined by the region that displayed the largest ERP component after averaging over all cue types, conditions, and age groups. The right hemisphere ROI was used for P1 and alpha band analysis, the left hemisphere ROI for the $\mathrm{N} 1$, and the central ROI for the P3 and CNV. Although the CNV is often reported at frontocentral regions (Brunia, 1988), it may also be observed in posterior-central regions (Simson et al., 1977; van Boxtel and Brunia, 1994), which may reflect less motor-related expectation and more perceptual anticipatory processes in the visual domain (Ruchkin et al., 1986). Statistical analysis for EEG as well as behavioral data used a repeated-measures ANOVA with a Greenhouse-Geisser correction when appropriate. Post hoc analyses consisted of two-tailed $t$ tests.

\section{Results}

\section{Behavioral performance}

Very high accuracy was achieved by both age groups for all conditions ( $97 \%$ ); therefore, further behavioral analysis focused on response times (RTs), as summarized in Table 2. A four-way ANOVA was conducted on the RTs with condition (detection, go/no-go discrimination, forced-choice discrimination), foreperiod (long, short), cue (predictive, neutral), and age (younger, older) as factors. Main effects were observed for all four factors: condition $\left(F_{(2,76)}=76.13, p<0.001\right)$, foreperiod $\left(F_{(1,38)}=6.12\right.$, $p<0.05)$, cue $\left(F_{(1,38)}=5.94, p<0.05\right)$, and age $\left(F_{(1,38)}=7.11\right.$, $p<0.05)$. Two-way interactions were observed for condition $\times$ foreperiod $\left(F_{(2,76)}=11.44, p<0.001\right)$, cue $\times$ foreperiod $\left(F_{(1,38)}=17.20, p<0.005\right)$, cue $\times$ age $\left(F_{(1,38)}=11.06, p<\right.$ $0.005)$, and foreperiod $\times$ age $\left(F_{(1,38)}=5.81, p<0.05\right)$. Addition-

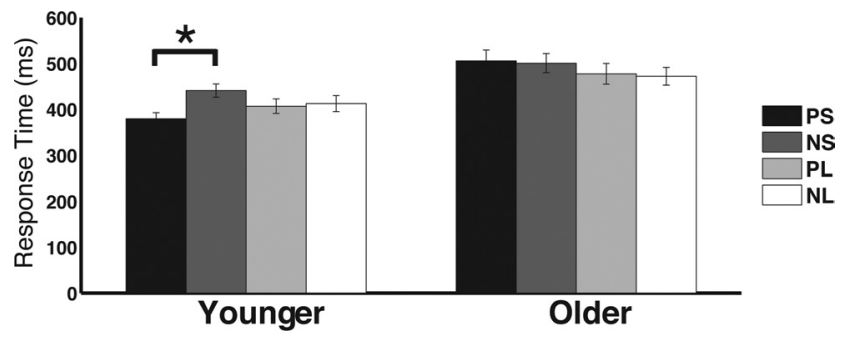

Figure 2. Summary of age-related changes in response time benefits from predictive cues Only younger adults benefit from predictive cues preceding a short foreperiod (PS). ${ }^{*} p<0.05$

ally, three-way interactions were observed for cue $\times$ foreperiod $\times$ age $\left(F_{(1,38)}=16.90, p<0.005\right)$ and condition $\times$ foreperiod $X$ age $\left(F_{(2,76)}=4.19, p<0.05\right)$. A four-way interaction was not observed $\left(F_{(2,76)}=1.07, p=0.35\right)$.

Post hoc $t$ tests were conducted to inform the cue $\times$ foreperiod $\times$ age interaction: predictive cues were compared with neutral cues for each age group and foreperiod length (collapsed across condition). Results showed that younger adults only used predictive cues for the short foreperiod (PS vs NS: $t_{(19)}=6.83$, $p<0.001$ ), not for the long foreperiod (PL vs NL: $t_{(19)}=0.80, p=$ 0.43 ), whereas older adults did not use the predictive cues to enhance performance for either short (PS vs NS: $t_{(19)}=0.45, p=$ 0.66 ) or long (PL vs NL: $t_{(19)}=0.52, p=0.61$ ) foreperiods (Fig. 2 ). To evaluate age-related differences further, a direct comparison of the cueing effect (NS - PS) between age groups confirmed that younger adults benefited more from cues predicting short foreperiods than older adults $\operatorname{did}\left(t_{(38)}=4.62, p<0.001\right)$, whereas there were no cueing differences between age groups for long foreperiods (NL $\left.-\mathrm{PL} ; t_{(38)}=0.89, p=0.38\right)$. Of note, the current results showed that neither younger nor older adults used the predictive cue for the long foreperiod (i.e., NL $=\mathrm{PL}$ ), replicating previous findings in younger adults in both the visual (Miniussi et al., 1999) and auditory (Stefanics et al., 2010) domains. This is likely due to the equated conditional probability of a target appearing following a long foreperiod regardless of the preceding cue type; PL cues do not provide additional information beyond NL cues once the short foreperiod time has elapsed. In summary, the results indicate that younger adults use predictive cues to benefit performance, whereas older adults do not use temporal cues to effectively allocate attention in time to benefit perceptual performance. The absence of a significant four-way interaction suggests that this interaction was not dependent on task, and thus not a function of manipulations in perceptual and motoric demands.

Post hoc $t$ tests were also conducted to inform the condition $X$ foreperiod $\times$ age interaction, although not explicitly a focus of the current study. The short and long foreperiod were contrasted for each condition and age group (collapsed across cue). Results show that both younger and older adults display faster RTs following a long foreperiod versus a short foreperiod for the detection condition (young: $t_{(19)}=2.13, p<0.05$; older: $t_{(19)}=3.20$, $p<0.005)$ and this effect was larger for older than for younger adults $\left(t_{(38)}=2.51, p<0.05\right)$. However, RT differences between the foreperiod lengths were not observed in either age group for the discrimination conditions (go/no-go discrimination, forcedchoice discrimination; $p>0.1$, each comparison). To explore age-related changes further, RTs were contrasted between the younger and older adults for each condition and foreperiod length (collapsed across cues). Results showed that, following a short foreperiod, younger adults respond faster than older adults 


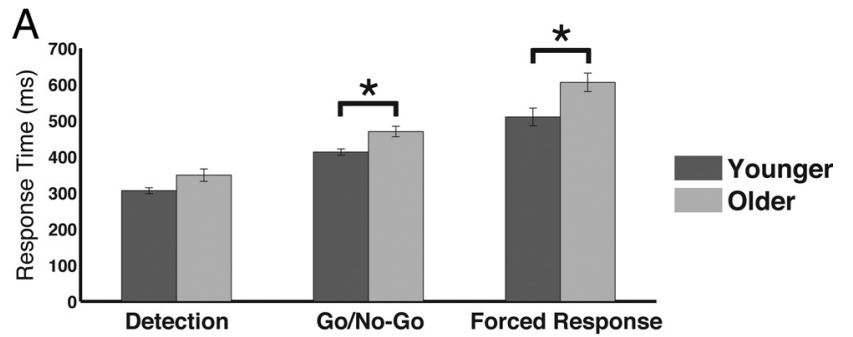

B

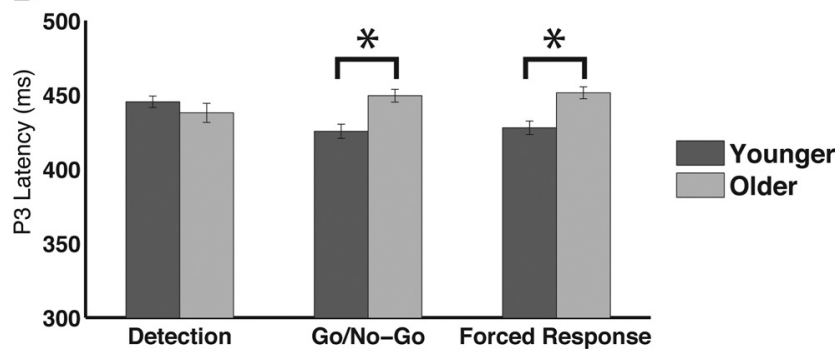

Figure 3. Age-dependent changes across conditions. $\boldsymbol{A}$, Response times following a long foreperiod were not different between age groups for the easiest task (detection). However, age-related slowing was observed during tasks that required more cognitive processing ( $\mathrm{g}$ / no-go and forced choice). $\boldsymbol{B}$, Similar to response times, the latency of the $P 3$ was delayed in older adults only during tasks that required more cognitive processing than detection. ${ }^{*} p<0.05$.

regardless of condition ( $p<0.05$, each comparison). However, following a long foreperiod, younger and older adults produce comparable RTs during the detection condition $\left(t_{(38)}=1.65, p>\right.$ 0.1 ), whereas younger adults respond faster during the go/no-go $\left(t_{(38)}=1.97, p=0.057\right)$ and forced-choice discrimination $\left(t_{(38)}=2.40, p<0.05\right)$ conditions (Fig. 3A). Together, these results suggest that older adults perform equivalently to younger adults when the following two conditions are met: (1) task with simple perceptual processing and motoric response (detection) and (2) longer time required before a response (long foreperiod). However, in the setting of a short foreperiod or increased perceptual and motoric demands at either foreperiod length, age-related response slowing is manifest.

\section{Cue processing}

The P1 ( 100 ms after stimulus onset) and N1 ( 170 ms after stimulus onset) components of the visual ERP are neural measures of activity in visual association cortical areas and are modulated by spatial-, feature- and object-based attention (Hillyard and Münte, 1984; Mangun, 1995; Gazzaley et al., 2005b; Schoenfeld et al., 2007; Zanto and Gazzaley, 2009). Thus, the P1 and N1 time-locked to the temporal cue stimuli were analyzed to assess whether age-related differences in visual processing of the cues may have contributed to performance differences. Mean amplitude and latency measures (Table 3) from the cue-evoked P1 and $\mathrm{N} 1$ were submitted to a four-way ANOVA with condition (detection, forced choice, go/no-go), foreperiod (long, short), cue (predictive, neutral), and age (younger, older) as factors.

The $\mathrm{P} 1$ amplitude and latency each elicited a foreperiod $\times$ age interaction (amplitude: $F_{(1,38)}=5.19, p<0.05$; latency: $F_{(1,38)}=$ 5.81, $p<0.05$ ). Post hoc $t$ tests revealed that the difference of P1 amplitude and latency between short and long foreperiods (long - ahort; collapsed across condition and cue) varied across age groups, such that both difference measures were greater in younger versus older adults (amplitude: $t_{(38)}=2.27, p<0.05$; latency: $\left.t_{(38)}=2.41, p<0.05\right)$. No other interaction or main effects were observed for the P1.
The N1 amplitude elicited a main effect for condition $\left(F_{(2,76)}=4.73, p<0.05\right)$, such that the cues in the go/no-go task yielded a smaller $\mathrm{N} 1$ than cues in the detection $\left(t_{(39)}=2.76, p\right.$ $0.01)$ and forced-choice $\left(t_{(39)}=2.58, p<0.05\right)$ tasks. Additionally, a foreperiod $\times$ cue interaction was observed $\left(F_{(1,38)}=6.40\right.$, $p<0.05)$, indicating that the PS N1 was larger than the PL N1 $\left(t_{(39)}=2.97, p<0.01\right)$ and NS was not different from NL. Thus, the N1 amplitude may serve as an index for temporal cue processing.

The N1 latency analysis yielded main effects for age $\left(F_{(1,38)}=\right.$ $8.52, p<0.01)$, cue $\left(F_{(1,38)}=12.97, p<0.001\right)$, and foreperiod $\left(F_{(1,38)}=4.66, p<0.05\right)$, such that it was delayed in older adults (Fig. 4) and peaked later following predictive cues, as well as during trials that preceded a long foreperiod. Additionally, a foreperiod $\times$ cue interaction was observed $\left(F_{(1,38)}=12.14, p<\right.$ $0.005)$, indicating that the $\mathrm{N} 1$ following a PL cue peaked later than PS $\left(t_{(39)}=3.54, p<0.005\right)$, NS $\left(t_{(39)}=4.56, p<0.001\right)$, and $\mathrm{NL}\left(t_{(39)}=5.25, p<0.001\right)$ cues. These results further suggest that the N1 serves as an index for temporal cue processing, and that this cue processing is delayed in older adults.

Of note, the absence of significant age $\times$ cue interactions for any of these neural measures to cue stimuli suggests that differences in cue processing do not account of age-related behavioral differences in temporal attention.

\section{Foreperiod activity}

Perhaps the most well documented neuroelectric signature of prestimulus temporal expectation is the CNV. The CNV is elicited during the foreperiod (i.e., time between cue and target; Walter et al., 1964) and is a low-frequency (slow) wave that becomes increasingly more negative as the time approaches when the impending target is expected (Macar and Vidal, 2004; Pfeuty et al., 2005). Thus, mean CNV amplitudes (Table 4) preceding the target stimuli were submitted to a four-way ANOVA with condition (detection, forced choice, go/no-go), foreperiod (long, short), cue (predictive, neutral), and age (younger, older) as factors. Main effects were observed for cue $\left(F_{(1,38)}=6.17, p<0.05\right)$ and foreperiod $\left(F_{(1,38)}=17.71, p<0.001\right)$. Two-way interactions were observed for foreperiod $\times$ cue $\left(F_{(1,38)}=6.20, p<0.05\right)$ and foreperiod $\times$ age $\left(F_{(1,38)}=9.77, p<0.005\right)$. Additionally, a three-way interaction was observed for cue $X$ foreperiod $X$ age $\left(F_{(1,38)}=6.38, p<0.05\right)$. A four-way interaction was not observed $\left(F_{(2,76)}=2.09, p=0.13\right)$.

Post hoc $t$ tests were conducted to inform the cue $\times$ foreperiod $\times$ age interaction. Comparable to the RT analysis, the $\mathrm{CNV}$ following predictive cues were compared with the CNV following neutral cues for each age group and foreperiod length (collapsed across condition). Results showed that PS cues elicit a larger (i.e., more negative) $\mathrm{CNV}$ relative to NS cues in younger adults $\left(t_{(19)}=\right.$ $5.09, p<0.001$; Fig. $5 A$ ), whereas no significant cueing effect was identified for the CNV in older adults $(p>0.1$; Fig. $5 B)$. Consistent with behavioral results, no cueing effect was observed following the long foreperiod for either age group $(p>0.4$, each comparison; Fig. 5C,D). Direct comparisons between the age groups show comparable CNV amplitudes for PS, NS, and NL cues $(p>0.15$, each comparison), whereas older adults elicit more negative CNV amplitude following PL cues $\left(t_{(38)}=2.51\right.$, $p<0.05)$. However, this result is difficult to interpret as both age groups responded similarly to NL cues, while neither age group displayed a cueing effect neurally or behaviorally following a long foreperiod (NL > PL). Importantly, the magnitude of the CNV cueing effect (NS - PS) was larger in younger relative to older adults $\left(t_{(38)}=4.20, p<0.001\right)$, which is consistent with the 
Table 3. Amplitudes (in $\mu \mathrm{V}$ ) and latencies (in ms) to cue stimuli at the P1 and N1

\begin{tabular}{|c|c|c|c|c|c|c|c|c|}
\hline \multirow[b]{3}{*}{ Cue type } & \multicolumn{8}{|l|}{ Cue stimuli } \\
\hline & \multicolumn{2}{|l|}{ P1 amplitude } & \multicolumn{2}{|l|}{ P1 latency } & \multicolumn{2}{|l|}{ N1 amplitude } & \multicolumn{2}{|l|}{ N1 latency } \\
\hline & Younger, mean (SE) & Older, mean (SE) & Younger, mean (SE) & Older, mean (SE) & Younger, mean (SE) & Older, mean (SE) & Younger, mean (SE) & Older, mean (SE) \\
\hline PS & $1.49(0.31)$ & $1.90(0.36)$ & $96(5)$ & $98(4)$ & $-4.10(0.64)$ & $-5.49(0.67)$ & $164(3)$ & $173(4)$ \\
\hline NS & $1.37(0.30)$ & $1.53(0.29)$ & $96(6)$ & $95(5)$ & $-3.69(0.73)$ & $-4.64(0.73)$ & $164(3)$ & $177(3)$ \\
\hline PL & $1.53(0.29)$ & $1.31(0.27)$ & $98(5)$ & $95(4)$ & $-3.31(0.62)$ & $-4.97(0.55)$ & $175(4)$ & $175(4)$ \\
\hline PS & $1.88(0.24)$ & $1.59(0.27)$ & $88(6)$ & $96(4)$ & $-3.89(0.68)$ & $-5.27(0.59)$ & $167(5)$ & $179(4)$ \\
\hline NS & $1.19(0.33)$ & $1.78(0.34)$ & $93(4)$ & $95(4)$ & $-3.49(0.68)$ & $-4.01(0.64)$ & $161(4)$ & $178(4)$ \\
\hline PL & $1.95(0.37)$ & $1.59(0.24)$ & $101(5)$ & $92(5)$ & $-2.62(0.60)$ & $-4.07(0.52)$ & $172(5)$ & $188(5)$ \\
\hline NL & $1.86(0.38)$ & $1.65(0.32)$ & $88(4)$ & $99(4)$ & $-4.24(0.68)$ & $-4.39(0.57)$ & $163(4)$ & $176(4)$ \\
\hline \multicolumn{9}{|c|}{ Discrimination } \\
\hline PS & $1.48(0.44)$ & $1.69(0.31)$ & $101(5)$ & $104(4)$ & $-3.98(0.66)$ & $-4.67(0.62)$ & $165(4)$ & $181(6)$ \\
\hline
\end{tabular}

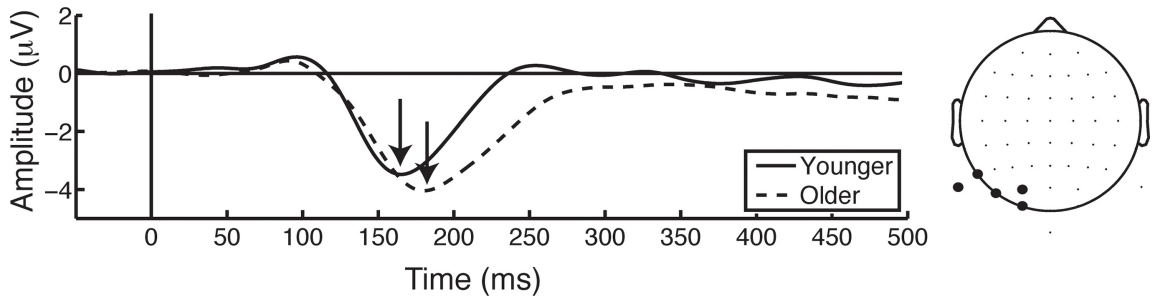

Figure 4. ERP to the cue from the left hemisphere R0I. Older adults show a delay at the $\mathrm{N} 1$ ( $\sim 170$ ms following cue onset). regions is modulated by attentional cues before an impending stimulus onset (Foxe et al., 1998; Worden et al., 2000; Bressler et al., 2008; Capotosto et al., 2009) to optimize subsequent perceptual performance (Ergenoglu et al., 2004; Hanslmayr et al., 2007; Van Dijk et al., 2008). Therefore, mean $\mathrm{z}$-scored alpha power (Table 4) preceding the target stimuli was also submitted to a four-way ANOVA. Main effects were observed for cue $\left(F_{(1,38)}=\right.$ Table 4. Mean CNV amplitudes (in $\mu \mathrm{V}$ ) and alpha power (z-scored) during the foreperiod

\begin{tabular}{|c|c|c|c|c|}
\hline \multirow[b]{3}{*}{ Cue type } & \multicolumn{4}{|l|}{ Foreperiod activity } \\
\hline & \multicolumn{2}{|l|}{ CNV amplitude } & \multicolumn{2}{|l|}{ Alpha power z-score } \\
\hline & Younger, mean (SE) & Older, mean (SE) & Younger, mean (SE) & Older, mean (SE) \\
\hline \multicolumn{5}{|l|}{ Detection } \\
\hline PS & $-1.51(0.24)$ & $-0.73(0.22)$ & $-0.38(0.10)$ & $-0.28(0.13)$ \\
\hline NS & $-0.35(0.23)$ & $-0.29(0.21)$ & $0.33(0.11)$ & $-0.06(0.15)$ \\
\hline PL & $-0.59(0.57)$ & $-0.81(0.31)$ & $0.89(0.18)$ & $0.18(0.09)$ \\
\hline NL & $0.26(0.33)$ & $-0.84(0.28)$ & $0.65(0.19)$ & $0.05(0.11)$ \\
\hline \multicolumn{5}{|l|}{ Go/no-go } \\
\hline PS & $-0.93(0.31)$ & $-0.77(0.21)$ & $-0.59(0.09)$ & $-0.20(0.10)$ \\
\hline NS & $-0.26(0.24)$ & $-0.88(0.23)$ & $0.00(0.08)$ & $-0.02(0.11)$ \\
\hline PL & $1.21(1.10)$ & $-0.31(0.20)$ & $0.37(0.17)$ & $0.10(0.12)$ \\
\hline NL & $-0.22(0.41)$ & $-0.12(0.21)$ & $0.39(0.16)$ & $0.12(0.15)$ \\
\hline \multicolumn{5}{|c|}{ Discrimination } \\
\hline PS & $-0.59(0.19)$ & $-0.78(0.21)$ & $-0.34(0.12)$ & $-0.18(0.10)$ \\
\hline NS & $-0.19(0.24)$ & $-0.57(0.18)$ & $0.17(0.10)$ & $0.06(0.09)$ \\
\hline PL & $-0.24(0.38)$ & $-0.87(0.22)$ & $0.43(0.15)$ & $0.10(0.11)$ \\
\hline NL & $-0.12(0.31)$ & $-0.46(0.31)$ & $0.58(0.16)$ & $0.18(0.14)$ \\
\hline
\end{tabular}

behavioral finding that younger adults use cues to enhance performance, whereas older adults do not use predictive information to help allocate attention in time (Fig. 2). Of note, similar $\mathrm{CNV}$ results were observed at a frontocentral ROI (AFZ, FZ, FCZ, F1, F2). Although the frontal ROI findings were less pronounced, they corroborate the findings from the posterior $\mathrm{CNV}$ and behavioral data to indicate an age-related decline in attentional allocation.

Prestimulus alpha $(8-12 \mathrm{~Hz})$ activity is often attributed to the biasing of sensory processing areas, such that power in visual
42.44, $p<0.001)$, foreperiod $\left(F_{(1,38)}=33.71, p<0.001\right)$, and age $\left(F_{(1,38)}=4.13, p<0.05\right)$. Two-way interactions were observed for cue $\times$ age $\left(F_{(1,38)}=9.60, p<0.005\right)$, foreperiod $\times$ age $\left(F_{(1,38)}=\right.$ $8.21, p<0.01)$, and foreperiod $\times$ cue $\left(F_{(1,38)}=26.05, p<0.001\right)$. Additionally, three-way interactions were observed for cue $\times$ foreperiod $\times$ age $\left(F_{(1,38)}=5.90, p<0.05\right)$ and condition $\times$ foreperiod $\times$ cue $\left(F_{(2,76)}=4.27, p<0.05\right)$. A four-way interaction was not observed $\left(F_{(2,76)}=1.00 p=0.37\right)$.

Post hoc analysis to evaluate the cue $\times$ foreperiod $\times$ age interaction indicated that PS cues elicited reduced alpha power relative to NS cues, in both younger $\left(t_{(19)}=6.29, p<0.001\right.$; Fig. $\left.6 A\right)$ and older $\left(t_{(19)}=3.36, p<0.005\right.$; Fig. $\left.6 B\right)$ adults, whereas alpha activity was not modulated by cues preceding a long foreperiod in either age group ( $p>0.7$ for younger and older adults; Fig. $6 C, D)$. However, the magnitude of alpha modulation for the short foreperiod (PS - NS) was reduced in older compared with younger adults $\left(t_{(38)}=3.38, p<0.005\right)$. These results indicate that both younger and older adults use PS cues to modulate pretarget alpha, but this temporal cueing effect is diminished in aging.

The absence of a significant four-way interaction for either the $\mathrm{CNV}$ or pretarget alpha suggests that this interaction was not dependent on task demands.

\section{Target processing}

The P3 has been shown to be influenced solely by temporal expectation, such that the amplitude is enhanced and the latency of the P3 to target stimuli is speeded when a target is expected at a prespecified point in time (Miniussi et al., 1999). Therefore, mean amplitude and latency measures (Table 5) for the targetevoked P1, N1, and P3 were submitted to separate four-way ANOVAs with condition (detection, forced choice, go/no-go), 
foreperiod (long, short), cue (predictive, neutral), and age (younger, older) as factors. The P1 amplitude elicited main effects for cue $\left(F_{(1,38)}=4.15, p<0.05\right)$, foreperiod $\left(F_{(1,38)}=19.80, p<0.001\right)$, and a cue $\times$ foreperiod interaction $\left(F_{(1,38)}=\right.$ $7.27, p<0.05)$. Post hoc analysis indicated that the P1 amplitude following PL and NL cues were equivalent $(p>0.7)$; however, both elicited smaller amplitudes than the P1 following NS cues $(p<0.05$, each comparison), while the $\mathrm{P} 1$ following PS cues was larger than all other cued types ( $p<0.05$, all comparisons). No agerelated effects or interactions were observed for the target $\mathrm{P} 1$ amplitude. The P1 latency yielded a condition $\times$ foreperiod interaction $\left(F_{(2,76)}=3.57, p<0.05\right)$, as well as an age $\times$ foreperiod interaction $\left(F_{(1,38)}=4.88, p<0.05\right)$. Post hoc analysis indicated that in younger adults, the P1 following a long foreperiod was faster than the P1 following a short foreperiod $\left(t_{(19)}=2.52, p<0.05\right)$, and this effect was not observed in older adults. However, the P1 in younger adults was not significantly faster than the P1 in older adults following either length of foreperiod $(p>$ 0.4 , each comparison).

Analysis of the N1 amplitude showed main effects for condition $\left(F_{(2,76)}=3.35\right.$, $p<0.05)$ and foreperiod $\left(F_{(1,38)}=44.79\right.$, $p<0.001)$ and a condition $\times$ age interaction $\left(F_{(2,76)}=3.35, p<0.001\right)$. Post hoc analysis showed that younger adults display larger $\mathrm{N} 1$ amplitude during the forced-choice task compared with detection $\left.t_{(19)}=2.90, p<0.005\right)$, where older adults do exhibit this differential response based on task $(p>0.7)$. However, direct comparisons between age groups indicate no age-related differences in the $\mathrm{N} 1 \mathrm{am}$ plitude for each task ( $p>0.1$, each comparison). Analysis of the N1 latency showed a main effect for condition $\left(F_{(2,76)}=\right.$ $3.19, p<0.05)$, such that it was slower during the forced-choice task compared with detection $\left(t_{(39)}=2.40, p<0.05\right)$ and go/no-go $\left(t_{(39)}=1.89, p=0.06\right)$, which were not different from each other $(p>$ $0.5)$. This suggests that generalized slowing of perceptual processing with aging does not account for the delay observed at the cue-evoked N1, as the target-evoked $\mathrm{P} 1$ and N1 display no age-related changes.

Analysis of the P3 amplitude elicited main effects for cue $\left(F_{(1,38)}=20.21, p<\right.$ $0.001)$ and condition $\left(F_{(2,76)}=3.43, p<\right.$ 0.05 ), indicating that the $\mathrm{P} 3$ was larger when targets were predictively cued, and smaller for the forced-choice task compared with detection and go/no-go tasks, which were not different from each other.

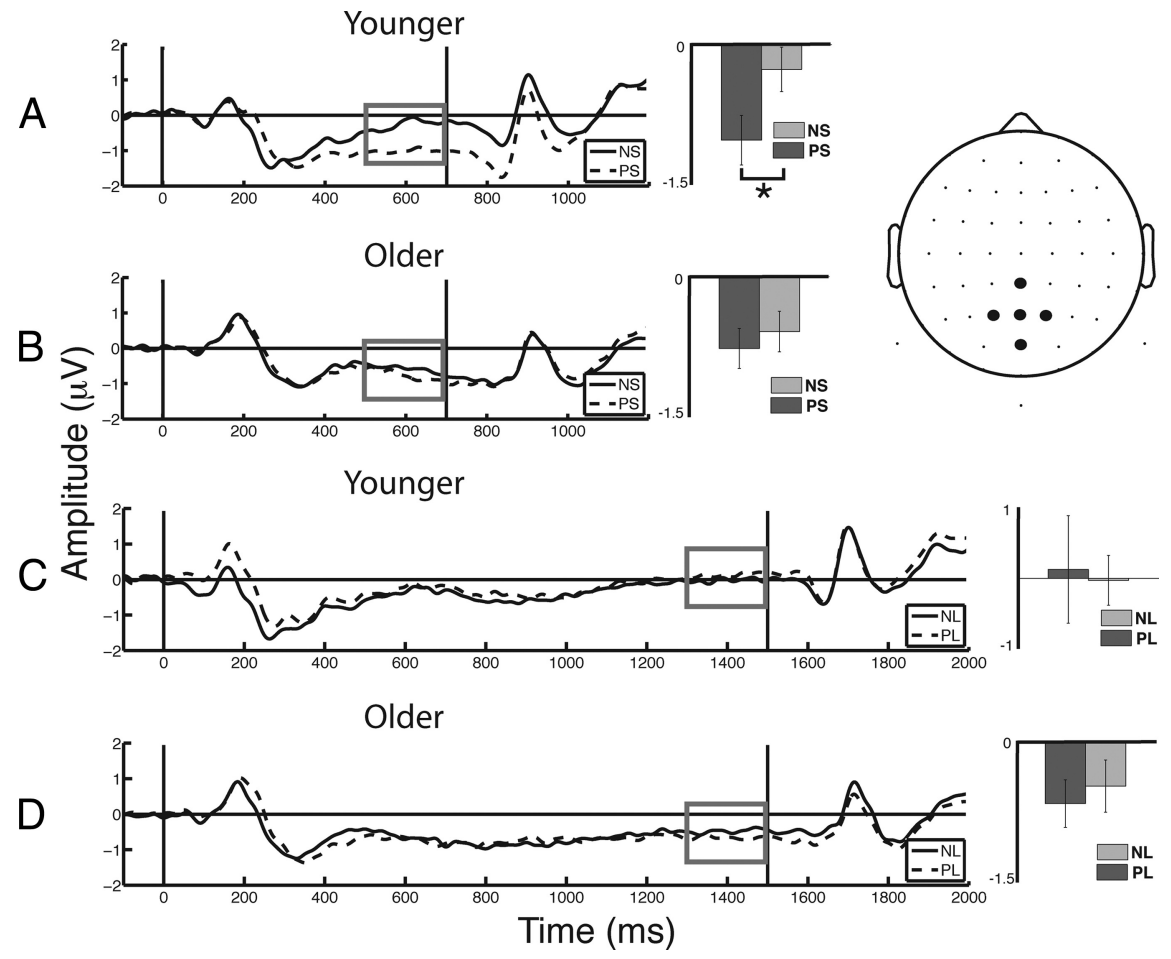

Figure 5. ERPs from the central-posterior ROI. Vertical black lines indicate stimulus onset (cue, $0 \mathrm{~ms}$; target, 700 or $1500 \mathrm{~ms}$ ). Measures of the terminal CNV (gray box) were subject to analysis. $A$, Younger adults elicited a larger CNV following PS compared with NS. $\boldsymbol{B}$, Older adults did not show any cue-related differences in their CNV (NS vs PS). C, D, Younger ( $\boldsymbol{C}$ and older (D) adults did not show cue-related differences in their CNV during the long foreperiods. ${ }^{*} p<0.001$.

A
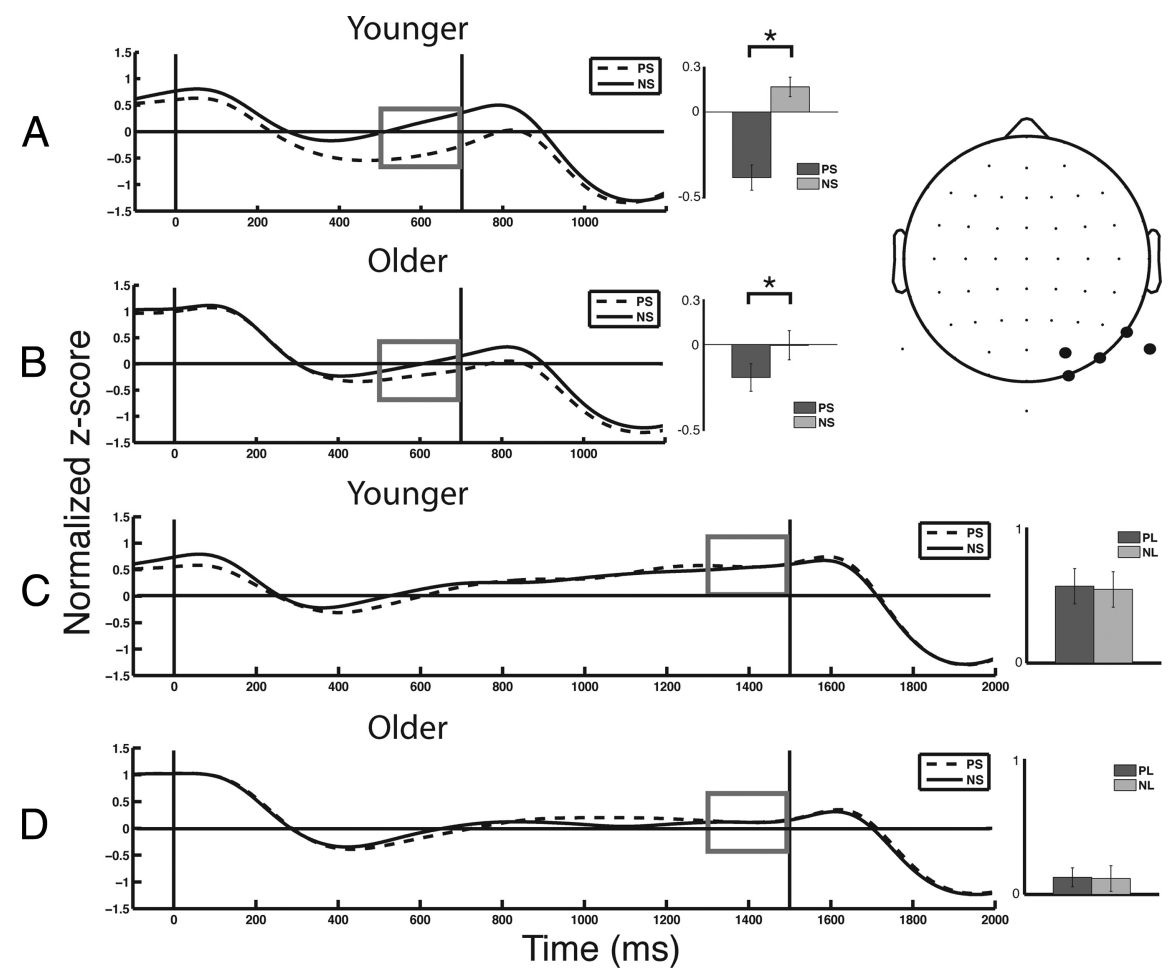

Figure 6. Alpha $(8-12 \mathrm{~Hz})$ activity from the right posterior R0l. Vertical black lines indicate stimulus onset (cue, $0 \mathrm{~ms}$; target, 700 or $1500 \mathrm{~ms}$ ). Measures of alpha activity (gray box) were subject to analysis. $A$, Younger adults elicited more negative alpha activity following PS compared with NS. B, Older adults also showed more negative alpha activity following PS compared with NS, although the magnitude of modulation is less than younger adults. $\boldsymbol{C}, \boldsymbol{D}$, Younger $(\boldsymbol{C})$ and older $(\boldsymbol{D})$ adults did not show cue-related differences in their alpha activity during the long foreperiods. ${ }^{*} p<0.005$. 
Table 5. Amplitudes (in $\mu \mathrm{V}$ ) and latencies (in ms) to target stimuli at the $\mathrm{P} 1, \mathrm{N1}$, and $\mathrm{P3}$

\begin{tabular}{|c|c|c|c|c|c|c|c|c|c|c|c|c|}
\hline \multirow[b]{3}{*}{ Cue type } & \multicolumn{12}{|c|}{ Target simuli } \\
\hline & \multicolumn{2}{|c|}{ P1 amplitude } & \multicolumn{2}{|l|}{ P1 latency } & \multicolumn{2}{|l|}{ N1 amplitude } & \multicolumn{2}{|l|}{ N1 latency } & \multicolumn{2}{|c|}{ P3 amplitude } & \multicolumn{2}{|l|}{ P3 latency } \\
\hline & $\begin{array}{l}\text { Younger, } \\
\text { mean (SE) }\end{array}$ & $\begin{array}{l}\text { Older, } \\
\text { mean (SE) }\end{array}$ & $\begin{array}{l}\text { Younger, } \\
\text { mean (SE) }\end{array}$ & $\begin{array}{l}\text { Older, } \\
\text { mean (SE) }\end{array}$ & $\begin{array}{l}\text { Younger, } \\
\text { mean (SE) }\end{array}$ & $\begin{array}{l}\text { Older, mean } \\
\text { (SE) }\end{array}$ & $\begin{array}{l}\text { Younger, } \\
\text { mean (SE) }\end{array}$ & $\begin{array}{l}\text { Older, } \\
\text { mean (SE) }\end{array}$ & $\begin{array}{l}\text { Younger, } \\
\text { mean (SE) }\end{array}$ & $\begin{array}{l}\text { Older, } \\
\text { mean (SE) }\end{array}$ & $\begin{array}{l}\text { Younger, } \\
\text { mean (SE) }\end{array}$ & $\begin{array}{l}\text { Older, } \\
\text { mean (SE) }\end{array}$ \\
\hline \multicolumn{13}{|c|}{ Detection } \\
\hline PS & $3.75(0.56)$ & $2.87(0.44)$ & $128(3)$ & $119(5)$ & $-4.52(0.74)$ & $-4.16(0.82)$ & $199(4)$ & $188(6)$ & $2.17(0.37)$ & $1.51(0.39)$ & $436(8)$ & $435(13)$ \\
\hline NS & $2.91(0.50)$ & $2.47(0.36)$ & $118(5)$ & $121(4)$ & $-3.97(0.77)$ & $-3.37(0.78)$ & $188(6)$ & $190(6)$ & $1.15(0.40)$ & $1.11(0.45)$ & $458(6)$ & $434(13)$ \\
\hline \multicolumn{13}{|c|}{ Go/no-go } \\
\hline PS & $3.85(0.48)$ & $3.01(0.49)$ & $122(4)$ & $119(5)$ & $-5.20(0.78)$ & $-3.26(0.71)$ & $197(4)$ & $194(6)$ & $2.20(0.35)$ & $1.65(0.35)$ & $444(6)$ & $454(8)$ \\
\hline NS & $2.70(0.44)$ & $2.71(0.50)$ & $113(6)$ & $113(6)$ & $-4.97(0.83)$ & $-3.74(0.67)$ & $192(5)$ & $200(6)$ & $1.44(0.39)$ & $1.16(0.30)$ & $435(7)$ & $448(6)$ \\
\hline PL & $2.71(0.57)$ & $1.96(0.40)$ & $118(4)$ & $122(5)$ & $-5.95(0.95)$ & $-4.87(0.93)$ & $193(5)$ & $198(7)$ & $1.51(0.35)$ & $1.18(0.32)$ & $402(13)$ & $454(10)$ \\
\hline $\mathrm{NL}$ & $2.57(0.36)$ & $2.14(0.40)$ & $114(7)$ & $116(5)$ & $-6.47(0.81)$ & $-4.08(0.75)$ & $198(4)$ & $187(7)$ & $1.48(0.39)$ & $1.20(0.29)$ & $420(9)$ & $442(10)$ \\
\hline \multicolumn{13}{|c|}{ Discrimination } \\
\hline
\end{tabular}

Additionally, a cue $\times$ foreperiod interaction was observed $\left(F_{(1,38)}=\right.$ $10.70, p<0.005)$. Post hoc analysis showed that the P3 was largest following PS targets compared with PL, NS, and NL targets $(p<$ 0.001 , each comparison), which were not different from each other.

Analysis of the P3 latency displayed a foreperiod main effect $\left(F_{(1,38)}=10.12, p<0.005\right)$, such that the P3 was faster following a long foreperiod. Moreover, a foreperiod $\times$ age $\left(F_{(1,38)}=15.39\right.$, $p<0.001)$ and a condition $\times$ age $\left(F_{(2,76)}=4.07, p<0.05\right)$ interaction was observed. Post hoc analysis showed that the P3 following a long foreperiod was faster in younger adults compared with the P3 following a short foreperiod $\left(t_{(19)}=4.34, p<\right.$ $0.001)$ and faster than the P3 in older adults regardless of foreperiod length (short: $t_{(38)}=2.95, p<0.01$; long: $t_{(38)}=2.95, p<$ $0.01)$, which was not different from each other $(p>0.7)$. Furthermore, younger adults elicited a faster P3 than older adults during the forced-choice $\left(t_{(38)}=2.75, p=0.009\right)$ and go/no-go $\left(t_{(38)}=2.81, p=0.008\right)$ conditions, whereas no age-related difference was observed during detection $\left(t_{(38)}=0.61, p>0.5\right.$; Fig. $3 B$ ). These results show the P3 latency effects to the target were similar to the performance results in that younger and older adults process the targets and respond to them in a comparable fashion for the easiest condition (detection), but age-related delays in processing and response time appear as task demands increase.

Of note, no significant age $\times$ cue interaction was observed for any of these target measures, revealing that the differences in temporal attention performance are not due to differential perceptual processing of the targets.

\section{Relationship between cue processing and foreperiod activity}

Thus far we have shown that the cue-evoked N1 is modulated by cued information and that it is slower in older adults. Interestingly, the target-evoked N1 was not delayed in older adults, suggesting a specific delay in the older adults' ability to process and possibly extract cued information. We have also shown that older adults do not use cued information to modulate the CNV amplitude or alpha power following short foreperiods, as the younger adults did. Therefore, it is possible that the short foreperiod was too brief a time for older adults to engage expectation-driven neural mechanisms because they required more time than younger adults to extract the cued information. To evaluate whether the $\mathrm{N} 1$ for cue processing was related to the magnitude of the $\mathrm{CNV}$ or alpha power preceding the target, a regression analysis was conducted for each cue type and foreperiod length (collapsed across condition). No significant correlation was observed between the amplitude or latency of the N1 and the amplitude of the CNV or alpha power ( $p>0.1$, all comparisons). Thus, there is no evidence that cue-related changes in pretarget neural measures of expectation are attributable to early visual processing delays to the cue.

\section{Discussion}

The current study used a temporally cued, target-response task to assess age-dependent changes in temporal attention and alterations in neural mechanisms that underlie performance deficits. The results indicated that, regardless of perceptual and motoric task demands, younger adults used temporal cues to enhance performance, such that RT was faster when cued for a short foreperiod relative to neutral cues, while older adults did not benefit from this predictive information. Moreover, older adults exhibited an alteration in two neural markers of expectation during the foreperiod (i.e., cueing effects on the CNV and alpha power). These parallel three-way interactions (cue $\times$ foreperiod $X$ age) for behavioral and neural data converge to indicate that independent of task complexity, the ability to allocate attention to a prespecified point in time is detrimentally affected by normal aging.

\section{Age-related deficit in attentional orienting to points in time}

The behavioral and neural results of the current study corroborate previous reports that younger adults use temporal cueing to enhance detection performance (Miniussi et al., 1999), and extend these findings by showing this same benefit exists for discrimination tasks consistently across two motoric response manipulations. Notably, the data further reveal that older adults do not use temporal cues to improve performance, regardless of the perceptual or motor demands of the task. We interpret these findings to reflect a deficit in older adults' ability to engage expectation mechanisms to guide optimal performance.

The current paradigm required rapid attentional allocation, and so the possibility exists that an expectation deficit might not be evident with a longer foreperiod. Interestingly, recent research 
using a $6 \mathrm{~s}$ foreperiod indicates that older adults have a deficit in expectation-based neural modulation when cued for object category (Bollinger et al., 2011), similar to the current findings with a shorter foreperiod. Therefore, the duration of the foreperiod may not the source for the observed decline in temporal orienting.

The possibility should also be considered that this age-related finding reflects differences in strategy, such that younger adults use temporal cues to guide behavior, whereas older adults dismiss them and rely solely on conditional probability (i.e., if the target does not follow a short foreperiod, then it must follow a long foreperiod). However, three findings indicate that this is not the case. First, conditional probability effects were not observed in either age group for the discrimination tasks (go/no-go, forcedchoice); thus, age-related differences in these tasks cannot be explained by older adults using a conditional probability strategy. Second, cue-evoked N1 amplitude and latency measures were modulated by the nature of the cued information in both age groups, indicating that the temporal cues were processed and not missed or dismissed. Finally, alpha activity preceding the target was modulated by PS relative to NS cues in both age groups regardless of task, it was just more so for younger adults, further indicating that both younger and older adults processed the predictive temporal cue based on its meaning to some extent. Together, we conclude that the inability to orient attention to specific points in time in the older adult population is not the result of differences in strategy.

In considering whether the current results are influenced by age-related deficits in perceptual or motoric abilities, it should first be noted that both RT and the P3 to target stimuli are delayed in older adults as a function of task complexity (Fig. 3). This supports previous research indicating that advanced age is associated with slower performance on a wide range of speeded tasks, and that slowing is exaggerated with increased task complexity (Kok, 2000; Salthouse, 2000; Drag and Bieliauskas, 2010). Consistent with this, when task demands were minimal (i.e., the detection task) and temporal cues were no longer relevant (i.e., at long foreperiods neither age group used the cue), RT and P3 latency were comparable between age groups, suggesting that simple motor and perceptual processes are preserved, while more complex processes decline in aging. It has been suggested that age-related slowing in simple repetitive tasks is mainly related to slowing at the stage of perceptuo-motor processes in mid-age and after 60 years of age, to additional decline of attention (Godefroy et al., 2010). Nonetheless, the absence of a four-way interaction indicates that the perceptual and motoric manipulations did not differentially affect the older adults inability to use the temporal cues. Thus, the current results support the hypothesis that older adults have difficulties preparing for uncertain events (Salthouse, 1985), which is independent of diminished perceptual and motor abilities.

\section{Neural mechanisms of temporal attention deficits in aging}

Overlapping frontal, parietal, and motor networks have been observed to be activated when directing attention to points in time (Coull and Nobre, 1998). These networks encompass the dorsolater and ventrolateral prefrontal cortices, premotor cortex, interparietal sulcus, visual cortex, thalamus, and cerebellum. This indicates both perceptual and motor regions are used for temporal processing (Nobre et al., 2007).

EEG and ERP studies of temporal expectations show that temporal orienting cues trigger anticipatory brain states thought to reflect changes in perceptual and motor preparation involving sharpening of CNV and increased desynchronization of activity in the alpha band (Miniussi et al., 1999; Praamstra et al., 2006; Rohenkohl and Nobre, 2011). Some of the anticipatory processes regulating neuronal excitability in temporal orienting tasks may be similar to those that occur in response to the natural temporal regularity within contexts of rhythmic stimulation (Canolty et al., 2006; Nobre et al., 2007; Schroeder and Lakatos, 2009). Here we show age-related alterations in $\mathrm{CNV}$ and alpha modulation during the foreperiod and interpret these as neural signatures of a temporal expectation deficit in aging.

Source localization of the CNV has indicated that it reflects both motor cortex engagement (Rektor, 2002; Nagai et al., 2004) and frontoparietal network involvement (Gómez et al., 2007), which falls in line with the proposed role of the CNV in motor and perceptual expectation (Loveless and Sanford, 1974; Brunia and Damen, 1988). Similarly, alpha activity is under the influence of frontoparietal neural networks (Capotosto et al., 2009) and a decrease in alpha activity is thought to be a signature of visual cortex excitability for an impending stimulus (Romei et al., 2008). Thus, the temporal expectation deficit in aging may stem from a deterioration of frontoparietal attentional networks, as both the CNV and alpha modulation may reflect a degraded influence of top-down control on motor and perceptual expectation-driven processes. This is supported by recently documented age-related changes in frontoparietal networks during the expectation period of a category cueing task (Bollinger et al., 2011).

In addition to spectral power, phase information is also related to cortical excitability and measures of expectation. Recent research has demonstrated alpha phase modulates gamma $(30-70 \mathrm{~Hz})$ (Osipova et al., 2008) and high gamma $(80-150 \mathrm{~Hz})$ (Voytek et al., 2010) amplitude, which may explain why alpha phase also predicts subsequent visual perception (Busch et al., 2009; Mathewson et al., 2009; Busch and VanRullen, 2010). Moreover, in the context of rhythmic stimulation, lower frequency delta $(0.5-3 \mathrm{~Hz})$ phase mediate levels of expectancy as measured through speeded response times in macaques (Lakatos et al., 2008) and humans (Stefanics et al., 2010). Interestingly, the $\mathrm{CNV}$ resides within the delta frequency band, the amplitude of which inversely correlates with response times such that larger (i.e., more negative $\mathrm{CNV}$ amplitudes) result in shorter response times (Rohrbaugh and Gaillard, 1983). This result is analogous to the relationship between delta activity and response times in humans, as both negative phase and larger negative amplitude predicts faster response times (Stefanics et al., 2010). It was suggested that the CNV, similar to delta band activity, might reflect a lowfrequency cortical oscillation that is reset by a cue stimulus (Lakatos et al., 2008). However, further research is required to fully understand this relationship.

\section{Expectation deficit hypothesis of cognitive aging}

We propose the observed age-related behavioral and neural deficit in temporal attention is reflective of a more widespread expectation deficit underlying a diverse array of cognitive deficits that occur with normal aging. Here, we show an expectation deficit in the temporal domain using three different tasks, which manipulate perceptual demand (i.e., detection and discrimination) as well as motor execution demands (i.e., bimanual and selective unimanual). Spatial attention research using cues of an ensuing target's spatial location have indicated that response times in older adults do not benefit from cueing as much as in younger adults (Rabbitt, 1979; Hoyer and Familant, 1987). Previous research has also shown that older adults display attentional 
orienting deficits following object- and feature-based cues, which impact subsequent working memory performance (Gazzaley et al., 2005a, 2008; Zanto et al., 2010). Moreover, Bollinger et al. (2011) demonstrated age-related declines in object-based expectation mechanisms with a negative influence on working memory and long-term memory performance in older adults. These convergent results using different types of attention tasks (i.e., temporal, spatial, feature, object-based), performance measures (i.e., detection, discrimination, working memory, longterm memory), and motor requirements (i.e., bimanual, selective unimanual, no motor response) reveal that older adults do not effectively use expectation-based mechanisms to benefit task performance.

A failure in engaging expectation mechanisms may lead to muted neural responses to a stimulus compared with the scenario in which expectations are formed and a stimulus is matched to a predefined temporal template. A direct prediction of this hypothesis would be that older adults show less neural activity when surprised by an unexpected stimulus because novel stimuli would not deviate from processes that would otherwise be engaged by an expected template. Indeed, older adults yield fewer eye-blinks, as well as smaller N1 and P3 amplitudes, to startling sounds, even when stimuli are equated for an age-related decline in bottom-up sensitivity (Ford and Pfefferbaum, 1991; Ford et al., 1995). Additionally, infrequent (unexpected) visual and somatosensory stimuli yield smaller P3 amplitudes in older adults (Looren de Jong et al., 1989; Yamaguchi and Knight, 1991; Dujardin et al., 1993). While these results are typically interpreted as signatures of a deficit in attentional capture, this does not preclude the possibility that it stems from a decline in expectation-based processes.

\section{Conclusions}

The current neural and behavioral findings converge to show that only younger adults use temporal cues to enhance performance during detection, forced-choice discrimination, and go/no-go discrimination tasks. This reveals that older adults have a deficit in orienting attentional resources over time, independent of task demands. Overall, these results support the hypothesis that behavioral deficits in older adults may be the result of deficient expectation-based neural processes.

\section{References}

Bollinger J, Rubens MT, Masangkay E, Kalkstein J, Gazzaley A (2011) An expectation-based memory deficit in aging. Neuropsychologia 49:1466-1475.

Bressler SL, Tang W, Sylvester CM, Shulman GL, Corbetta M (2008) Topdown control of human visual cortex by frontal and parietal cortex in anticipatory visual spatial attention. J Neurosci 28:10056-10061.

Brunia CH (1988) Movement and stimulus preceding negativity. Biol Psychol 26:165-178.

Brunia CH, Damen EJ (1988) Distribution of slow brain potentials related to motor preparation and stimulus anticipation in a time-estimation task. Electroencephalogr Clin Neurophysiol 69:234-243.

Busch NA, VanRullen R (2010) Spontaneous EEG oscillations reveal periodic sampling of visual attention. Proc Natl Acad Sci USA 107:16048-16053.

Busch NA, Dubois J, VanRullen R (2009) The phase of ongoing EEG oscillations predicts visual perception. J Neurosci 29:7869-7876.

Canolty RT, Edwards E, Dalal SS, Soltani M, Nagarajan SS, Kirsch HE, Berger MS, Barbaro NM, Knight RT (2006) High gamma power is phaselocked to theta oscillations in human neocortex. Science 313:1626-1628.

Capotosto P, Babiloni C, Romani GL, Corbetta M (2009) Frontoparietal cortex controls spatial attention through modulation of anticipatory alpha rhythms. J Neurosci 29:5863-5872.

Coull JT, Nobre AC (1998) Where and when to pay attention: the neural systems for directing attention to spatial locations and to time intervals as revealed by both PET and fMRI. J Neurosci 18:7426-7435.
Looren de Jong L, Kok A, Van Rooy JC (1989) Stimulus probablility and motor response in young and old adults: an ERP study. Biol Psychol 29:125-148.

Delis DC, Kramer JH, Kaplan E, Ober BA (2000) California Verbal Learning Test, Second Edition. San Antonio, TX: Psychological Corporation.

Dempster FN (1992) The rise and fall of the inhibitory mechanism: toward a unified theory of cognitive development and aging. Dev Rev 12:45-75.

Drag LL, Bieliauskas LA (2010) Contemporary review 2009: cognitive aging. J Geriatr Psychiatry Neurol 23:75-93.

Dujardin K, Derambure P, Bourriez JL, Jacquesson JM, Guieu JD (1993) P300 component of the event-related potentials (ERP) during an attention task: effects of age, stimulus modality and event probability. Int J Psychophysiol 14:255-267.

Ergenoglu T, Demiralp T, Bayraktaroglu Z, Ergen M, Beydagi H, Uresin Y (2004) Alpha rhythm of the EEG modulates visual detection performance in humans. Brain Res Cogn Brain Res 20:376-383.

Folstein MF, Folstein SE, McHugh PR (1975) “Mini-mental state": a practical method for grading the cognitive state of patients for the clinician. J Psychiatr Res 12:189-198.

Ford JM, Pfefferbaum A (1991) Event-related potentials and eyeblink responses in automatic and controlled processing: effects of age. Electroencephalogr Clin Neurophysiol 78:361-377.

Ford JM, Roth WT, Isaacks BG, White PM, Hood SH, Pfefferbaum A (1995) Elderly men and women are less responsive to startling noises: N1, P3, and blink evidence. Biol Psychol 39:57-80.

Foxe JJ, Simpson GV, Ahlfors SP (1998) Parieto-occipital similar to $10 \mathrm{~Hz}$ activity reflects anticipatory state of visual attention mechanisms. Neuroreport 9:3929-3933.

Fuster JM (1990) Inferotemporal units in selective visual attention and short-term memory. J Neurophysiol 64:681-697.

Gazzaley A, Cooney JW, Rissman J, D’Esposito M (2005a) Top-down suppression deficit underlies working memory impairment in normal aging. Nat Neurosci 8:1298-1300.

Gazzaley A, Cooney JW, McEvoy K, Knight RT, D’Esposito M (2005b) Topdown enhancement and suppression of the magnitude and speed of neural activity. J Cogn Neurosci 17:507-517.

Gazzaley A, Clapp W, Kelley J, McEvoy K, Knight RT, D’Esposito M (2008) Age-related top-down suppression deficit in the early stages of cortical visual memory processing. Proc Natl Acad Sci U S A 105:13122-13126.

Godefroy O, Roussel M, Despretz P, Quaglino V, Boucart M (2010) Agerelated slowing: perceptuomotor, decision, or attention decline? Exp Aging Res 36:169-189.

Gómez CA, Flores A, Ledesma A (2007) Fronto-parietal networks activation during the contingent negative variation period. Brain Res Bull 73:40-47.

Hanslmayr S, Aslan A, Staudigl T, Klimesch W, Herrmann CS, Bäuml KH (2007) Prestimulus oscillations predict between and within subjects. Neuroimage 37:1465-1473.

Hillyard SA, Münte TF (1984) Selective attention to color and location: an analysis with event-related brain potentials. Percept Psychophys 36:185-198

Hoyer WJ, Familant ME (1987) Adult age differences in the rate of processing expectancy information. Cogn Dev 2:59-70.

James W (1890) The principles of psychology. New York: Holt.

Kok A (2000) Age-related changes in involuntary and voluntary attention as reflected in components of the event-related potential (ERP). Biol Psychol 54:107-143.

Lakatos P, Karmos G, Mehta AD, Ulbert I, Schroeder CE (2008) Entrainment of neuronal oscillations as a mechanism of attentional selection. Science 320:110-113.

Lange K, Röder B (2006) Orienting attention to points in time improves stimulus processing both within and across modalities. J Cogn Neurosci 18:715-729.

Loveless NE, Sanford AJ (1974) Effects of age on contingent negative variation and preparatory set in a reaction-time task. J Gerontol 29:52-63.

Macar F, Vidal F (2004) Event-related potentials as indices of time processing: a review. J Psychophys 18:89-104.

Mangun GR (1995) Neural mechanisms of visual selective attention. Psychophysiology 32:4-18.

Mathewson KE, Gratton G, Fabiani M, Beck DM, Ro T (2009) To see or not to see: prestimulus alpha phase predicts visual awareness. J Neurosci 29:2725-2732. 
Miniussi C, Wilding EL, Coull JT, Nobre AC (1999) Orienting attention in time: modulation of brain potentials. Brain 122:1507-1518.

Moran J, Desimone R (1985) Selective attention gates visual processing in the extrastriate cortex. Science 229:782-784.

Nagai Y, Critchley HD, Featherstone E, Fenwick PB, Trimble MR, Dolan RJ (2004) Brain activity relating to the contingent negative variation: an fMRI investigation. Neuroimage 21:1232-1241.

Nobre A, Correa A, Coull J (2007) The hazards of time. Curr Opin Neurobiol 17:465-470.

Osipova D, Hermes D, Jensen O (2008) Gamma power is phase-locked to posterior alpha activity. PLoS One 3:e3990.

Pfeuty M, Ragot R, Pouthas V (2005) Relationship between CNV and timing of an upcoming event. Neurosci Lett 382:106-111.

Posner MI (1980) Orienting of attention. Q J Exp Psychol 32:3-25.

Posner MI, Walker JA, Friedrich FJ, Rafal RD (1984) Effects of parietal injury on covert orienting of attention. J Neurosci 4:1863-1874.

Praamstra P, Kourtis D, Kwok HF, Oostenveld R (2006) Neurophysiology of implicit timing in serial choice reaction-time performance. J Neurosci 26:5448-5455.

Rabbitt P (1979) Some experiments and a model for attentional selectivity with old age. In: Biological effects of aging (Baumeister F, ed). Hamburg: Springer.

Reitan RM (1958) Validity of the trail making test as an indicator of organic brain damage. Percept Mot Skills 8:271-276.

Rektor I (2002) Scalp-recorded Bereitschaftspotential is the result of the activity of cortical and subcortical generators: a hypothesis. Clin Neurophysiol 113:1998-2005.

Rohenkohl G, Nobre AC (2011) Alpha oscillations related to anticipatory attention follow temporal expectations. J Neurosci, in press.

Rohrbaugh JW, Gaillard AWK (1983) Sensory and motor aspects of the contingent negative variation. In: Tutorials in ERP research: endogenous components (Gaillard AW, Ritter W, eds), pp 269-310. Amsterdam: North Holland.

Romei V, Brodbeck V, Michel C, Amedi A, Pascual-Leone A, Thut G (2008) Spontaneous fluctuations in posterior alpha-band EEG activity reflect variability in excitability of human visual areas. Cereb Cortex 18: 2010-2018.

Ruchkin DS, Sutton S, Mahaffey D, Glaser J (1986) Terminal CNV in the absence of motor response. Electroencephalogr Clin Neurophysiol 63:445-463.

Salthouse TA (1985) Speed of behavior and its implications for cognition. In: Handbook of the psychology of aging (Birren JE, Schaie KW, eds), pp 400-426. New York: Van Nostrand Reinhold.

Salthouse TA (2000) Aging and measures of processing speed. Biol Psychol 54:35-54.

Schoenfeld MA, Hopf JM, Martinez A, Mai HM, Sattler C, Gasde A, Heinze HJ, Hillyard SA (2007) Spatio-temporal analysis of feature-based attention. Cereb Cortex 17:2468-2477.
Schroeder CE, Lakatos P (2009) Low-frequency neuronal oscillations as instruments of sensory selection. Trends Neurosci 32:9-18.

Simson R, Vaughan HG Jr, Ritter W (1977) Scalp topography of potentials in auditory and visual go-nogo tasks. Electroencephalogr Clin Neurophysiol 43:864-875.

Stefanics G, Hangya B, Hernádi I, Winkler I, Lakatos P, Ulbert I (2010) Phase entrainment of human delta oscillations can mediate the effects of expectation on reaction speed. J Neurosci 30:13578-13585.

Stroop JR (1935) Studies of interference in serial verbal reactions. J Exp Psych 18:643-662.

Tallon-Baudry C, Bertrand O (1999) Oscillatory gamma activity in humans and its role in object representation. Trends Cogn Sci 3:151-162.

Tombaugh TN (2004) Trail Making Test A and B: normative data stratified by age and education. Arch Clin Neuropsychol 19:203-214.

Vallesi A, McIntosh AR, Stuss DT (2009) Temporal preparation in aging: a functional MRI study. Neuropsychologia 47:2876-2881.

van Boxtel GJ, Brunia CH (1994) Motor and nonmotor components of the contingent negative variation. Int J Psychophysiol 17:269-279.

Van Dijk H, Schoffelen JM, Oostenveld R, Jensen O (2008) Prestimulus oscillatory activity in the alpha band predicts visual discrimination ability. J Neurosci 28:1816-1823.

Voytek B, Canolty RT, Shestyuk A, Crone NE, Parvizi J, Knight RT (2010) Shifts in gamma phase-amplitude coupling frequency from theta to alpha over posterior cortex during visual tasks. Front Hum Neurosci 4:191.

Walter WG, Cooper R, Aldridge VJ, McCallum WC, Winter AL (1964) Contingent negative variation: an electric sign of sensori-motor association and expectancy in the human brain. Nature 203:380-384.

Wechsler D (1981) Wechsler Adult Intelligence Scale-Revised Manual. New York: The Psychological Corporation.

Woodrow H (1914) The measurement of attention. Psych Monogr 17:1-158.

Worden MS, Foxe JJ, Wang N, Simpson GV (2000) Anticipatory biasing of visuospatial attention indexed by retinotopically specific alpha-band electroencephalography increases over occipital cortex. J Neurosci 20:RC63.

Yamaguchi S, Knight RT (1991) Age effects on the P300 to novel somatosensory stimuli. Electroencephalogr Clin Neurophysiol 78:297-301.

Yantis S, Jonides J (1990) Abrupt visual onsets and selective attention: voluntary versus automatic allocation. J Exp Psychol Hum Percept Perform $16: 121-134$.

Yesavage JA, Brink TL, Rose TL, Lum O, Huang V, Adey M, Leirer VO (1982) Development and validation of a geriatric depression screening scale: a preliminary report. J Psychiatr Res 17:37-49.

Zanto TP, Gazzaley A (2009) Neural suppression of irrelevant information underlies optimal working memory performance. J Neurosci 29:3059_ 3066.

Zanto TP, Toy B, Gazzaley A (2010) Delays in neural processing during working memory encoding in normal aging. Neuropsychologia 48:13-25. 